the proceerlings of this Board as embolled in the minutes and read at each quarterly meeting of the College constitute a very important collection of decisions. Certain By-laws, again, have been enacted from time to time by the College to define a line of conduct in particular contingencies, of which those at present in force may be found in Chap. XXVI. of the By-lans and Regulations of the College, a copy of which may be had on application to Mr. Fleming, the bedell, at the office of the College. Lastly, certain Resolutions of the College, passed generally on the recommendation of the Censors' Board and aimed at some growing offence against professional honour and good manners, have been printed and a general currency given them. It is such a Resolution that our correspondent has quoted, and it was passed by the College on July 27th, 1882.-ED. L.

\section{MATERNAL SYPHILIS.}

\section{To the Editors of THE LANCET.}

SIRs,-Many of the difficult questions connected with syphilis and maternity are dealt with in Dr. Coutts's able and interesting Hunterian Lecture in THE LANCET of April 11th. Quite unaware of Dr. Coutts's lecture and views I submitted to you a paper on the same subject on March 25th, approached rather from the gynæcological side, in which $\mathbf{i}$ ventured to remark on the prevalence and manifestations of syphilis in married women subsequently to abortion or delivery, and I attempted to urge the primary origin of syphilis in the mether rather than the "paternal syphilis" of the foetus with "syphilis by conception" in the mother. Dr. Coutts states that "all observers are agreed in the fact that a very large proportion of the mothers of syphilitic infants exhibit no outward evidence of the complaint even after prolonged and careful search." Dr. Coutts mentions 100 mothers who showed manifestations and 100 who were apparently free from syphilis. This percentage agrees with the figures of Mr. J. Hutchinson, who also has stated: "It is exceptional for such mothers to suffer from ostensible syphilis." Such statements as these have considerably perplexed me, for while I have been willing to admit apparent immunity in the mothers of syphilitic children brought to children's hospitals, I have been very much struck with the constant and spontaneous complaint of mothers who in gynæcological practice attribute their ill-health to abortion or confinement with no history of previous illness. Such complaints may be classed as debility, general ill-health, severe headaches, loss of or thinning of hair, sore throats, eruptions, palmar psoriasis, subinvolution and prolapse, leucorrbœa and hyperæmia of the vaginal mucous membrane, menorrhagia, erosions of the os, endometritis, chronic ovarian and tubal disease, and superficial sores of the anus and affections of the rectum. If these are not ostensible signs of syphilitic infection they in many cases are a sequel to a syphilitic pregnancy, while gummata, as in Charrier's case, and diseases of the bones and nervous system are by no means uncommon in married women in whom no suspicion of syphilis has arisen, but who have been pregnant by a husband who has had syphilis in early life. I regret I am unable at present to give complete and comparative statistics; I am, however, indebted to Mr. Henry Lee for kind permission to make use of his case-books, and I have collected a sufficient number of cases myself to satisfy me that ill-health in women subsequently to a syphilitic conception is far more common than is supposed, and that the views of Charrier, Cullerier, Notta, and others, who hold that "every syphilitic child is born of a syphilitic mother," are worthy of greater clinical recognition. A. Fournier states, "Syphilis in the child nearly always implies syphilis in the mother"; while Mr. Hutchinson himself, in interpreting Colles' views, sets forth that immunity and syphilisation are synonymous, and that the possibility of later manifestations cannot be excluded. Moreover, the works of Diday, Tyler Smith, and L. Parker clearly demonstrate the importance and recognition of syphilis in the mother subsequently to a syphilitic conception. If a mother is thus capable of being infected, it is obvious that the power of transmission to the offspring outlasting that of direct infection of the mother is of small significance.

The theoretical explanation of syphilis in the foctus and in the mother is possibly of second importance to the clinical recognition of syphilis in parous women. At the same time it is of such interest that it compels attention. I confess "paternal syphilis" and "syphilis by conception" do not satisfy me. The absence of primary disease in the mother applies to both paternal and maternal origin, for in nulliparous women primary disease may be so slight as to escape notice or altogether absent, while the lumbar glands may be enlarged and the inguinal glands normal. The absence of syphilis in the mother with manifest syphilis in the foetus is not conclusive, for absence of manifestations in a mother who has contracted it in the usual way is, as Dr. Coutts notes, not impossible. While Dr. Coutts considers there is no proof of the attenuation of the syphilitic virus in the male I confess I lean to the primary syphilisation of the wife, with partial or complete immunity, till pregnancy disturbs such latency and manifestations result subsequently to abortion or delivery. The following points seem to support such theory : : 1. It is no uncommon thing to find that intercourse and marriage lights up latent disease in men, and genital superficial lesions or modified urethritis appear. In a disease dependent on periodical activity of germs and production of antitoxin it seems almost unreasonable to doubt that the genital secretions of the male or the relapsing lesions of the penis are incapable of producing at a period of minimum activity syphilisation without obvious manifestations. 2. In a few cases that have presented themselves to me I have noted that pregnancy occurring in women who had previously suffered from syphilis, the syphilis which was latent was lighted up and manifested itself in ulcerated throat, genital sores, and eruption. 3. In pelvic absorption the extent of glandular distribution may considerably modify the rirus. and general infection.

The maternal origin of syphilis in the fotus in every case appears to be more reasonable than that the spermatozoon possesses the ability to infect the foetus and secondarily the mother. As regards this point I understand Dr. Coutts dis believes, as I do, in "syphilis by conception," but I do not follow him when he admits immunity by conception, partial or complete, which I take it, is syphilis by conception. One other point I would like to touch on in Dr. Coutts' valuable lecture. He explains Diday's "law of decreases" by immunity gained by the evolution of some chemical principle or antitoxin antagonistic to the growth of the germs. That is one explanation of immunity in general but I hold strongly to the theory of elimination of syphilis through the skin and secretions, and beg to quote Dr.J. F. Payne in his manual of General Pathology: "It is one of the oldest traditions in medicine that diseases which produce an exanthematous eruption are thrown off by the skin, which, expressed in modern language, means that the poison, or micro-organism, is eliminated by exfoliated epidermis and by the cutaneous secretions. Considering the case of syphilis, there is nothing impossible or even improbable in this theory." I am, Sirs, yours faithfully,

JoHN A. SHAW-MACKENZIE, M.D. Lond., \&c.,

Formerly Registrar to the Victoria Children's Hospital, and late Pathologist and Physician to the Out.
April 13th, 1896.

\section{THE ETYMOLOGY OF MEASLES. To the Editors of THE LANCET.}

Sirs,-Dr. William Sykes, in a learned paper on the Origin of English Disease Names, ${ }^{1}$ which will have been read with general interest, has, in following Professor Skeat as to the derivation of "measles," taken up a position which I had already shown " to be untenable. Trench, in his "Select Glossary," had derived measles from the mediæval Latin miselli, diminutive of miser, meaning the leprous, although he did not explain how measles came to be associated with leprosy. Professor Skeat, in his " Etymological Dictionary" did not doubt--it is, indeed, beyond doubt-that miselli reappears in the Norman-French form of mesels, or mesles, or mezeals; but he rejected Trench's etymology of measles on the ground that it is not the same word as mesles. "The spelling with the simple vowel $e$ " he says, "instead of $e a$ or $a e$, makes all the difference. The confusion between the words is probably quite modern." Thi: bland assertion, improbable on the face of it, seeing that it relates to so inconstant a thing as spelling, has sufficed for Dr. Sykes, who thereupon pronounces

1 Thic Lancer', April 11th, 1896.

2 History of Epidemics in Britain, vol, i., p. 632, 1893. 
me to be "probably in error," as well as "dogmatically" so, in defending the old derivation of Trench and in making it intelligible by showing that Gaddesden had actually grouped the small spots of morbilli with the broad, dusky red spots on the legs of pauperes tt consumptivi, who were called "anglice mesles." I had already shown that the separation in orthography between mesles and measles asserted by Professor Skeat.had no existence. Four English writers of the Tudor period-Pace (in a letter of 1518), Skene, Cogan, and Lodge-use the forms merils, mesillis, or mesels, where they mean morbilli ; while four others-lily ot (1541), Phaer, Clowes, and Kellwaye-write the word with ea, or in the way that has become fixed by subsequent usage. There was no uniformity: how could anyone look for it? Again, in the printed text of Shakespeare (who spelt his own name in five different ways) we find, "Those meazels which we disdain should tetter us" (Coriolanus; Act IV., Sc. 1), meaning a scurvy rabble, such as the mesells or lazars or beggars in the "Vision of Piers the Ploughman," of whom Professor Skeat was doubtless thinking. There was, in fact, only one word, with the usual latitude of spelling, still used occasionally in its original sense as late as the time of Shakespeare, but in its common use diverted to the meaning which Gaddesden's reference to it as a larger form of morbillous spots, in his chapter "De Variolis et Morbillis," had opened the way for. His "Rosa Anglica" had great authority for more than two centuries, and was printed almost as soon as printing began, so that it is not difficult to understand how mezils, or mesles, or meysyls, or measles should have got that specific meaning of morbilli which we find it to have about the beginning of the Tudor period. The first mention of an epidemic under that name which $I$ have noted is under the date of January, 1483, a certain infirmity then reigning, as was said, in Canterbury-namely, le meysyls, by reason of which the King did not accompany the Queen into the city. Dr. Sykes thinks that I had erred, as he supposes, by taking a too exclusively English standpoint in examining "the literature of the subject," meaning that I had paid no heed to the dictionary derivation of measles from the Dutch maeseln But how can one's point of view be too exclusively English when we discover the very fountain and origin of this English medical term in a freak of classification by Gaddesden? Measles having been shown to be the same word as mesles, the association of the latter with morbilli in the "Rosa Anglica" surely determines our priority over the Dutch.

$$
\text { I am, Sirs, yours faithfully, }
$$

C. CREIGHTON.

Great Ormond-street, London, W.C., April 13th, 1898.

\section{MIDWIVES' REGISTRATION. To the E'ditors of THE LANCET.}

Sirs, - We trust you will allow us to remind those members of the profession who are in favour of the education, registra. tion, and supervision of midwives that a Bill for securing these objects has been set down for reading in the House of Commons on May 6th. We desire to point out that no time should be lost in bringing the question under the notice of Members of Parliament and putting the case for legislation fairly before them. We are aware that a number of our brethren are opposed to such legislation, but we know also and we think it very important that Members of Parliament should know, that a very considerable number are in favour of it. The object of this letter is to urge the advocates of legislation to give their active support to the present Bill, which is identical with the amended Bill of Lord Balfour of Burleigh, introduced and read a second time in the House of Lords last year.

We are, Sirs, yours faithfully,

RoberT Boxalu, M.D.Cantab., \} Hon. Secs., Midwives'

Rowland HUMPHREYS,

Fellows-road, N. W., April 13th, 1896.

\section{To the Editors of THE LANCET.}

SIRS,-In your issue of April 4th your Liverpool corresponclent calls attention to the threatened dismissal of the risiting staff of the Liverpool Lying-in Hospital and to the appointing of midwives in their stead. This is a speedy nemesis, and should open the eyes of all practitioners who are in favour of the so.called registration of midwives. For some years the medical staff of this hospital has lectured and granted elegant diplomas to midwives. It has also stood by and allowed their district midwires to attend, on their sole responsibility, all out-door confinements, and without the aid of the district medical staff. Why, then, it is asked, can the visiting medical staff take valid objection to the plan being put into force in connexion with women confined in their hospital-which is, and has been, in force with their approbation among the home patients? Consistency of conduct is a valuable weapos, and it being forgotten is likely to recoil some day upon those who lay it aside. I do not, however, wish to blame unduly the visiting medical staff; I wish to use it as an illustration of the true and ulterior motives of the supporters of midwires registration. Thus Mr. H. C. Burdett suggested that no resident medical officer should be employed in small lying-in bospitals, but that his place should be taken by a midrif ${ }^{1}{ }^{1}$ This excludes resident medical officers. The committees of the City of London Lying-in and of the British Lying-in will not allow medical students to be trained in these hospitals in midwifery. This excludes medical students. In March, 1895. the Leicester board of guardians tried to appoint a midwife to take the place of their district medical officer, but the Local Government Board would not allo $N$ it. This proposed to do away with the district medical ofilicer's conducting pauper confinements. In November, 1895, the Peterborough guardians ("guardians" of the poor in inverted commas) sent a circular letter to all the other Poor-law guardians in England asking them to resolve: "That the members of the board are of opinion that it is desirable that boards of guardians shall have discretionary power of appointing duly qualified midwives for attendance at childbirth in place of the district medical offeer, subject to the condition as laid down in the Poor-law Board's Circular, No. 88." A most modest suggestion for those who shonld be the real guardians of sick women and infants! In the Hospital Annual, 1891, Mr. Burdett again writes: "It behove all midwives just now to be sure of obtaining a good certificate. ..... Every reasun which was brought forrard for the registration of medical men applies also to midwives. ....." Another modest remark! Dr. W. Grigg, lecturer to pupil midwives at Queen Charlotte's Huspital, said: "I am sure you will agree with me in hoping the day is not far distant when all midwifery will again fall into the hands of women." Why, I ask, should the lying-in room of the poor be again made the first stage to the chamber of death? The Midwives Institute, in its prospectns, modestly states: "As some confusion exists in the public mind as to the difference between midwives and monthly nurses, it may be weil to state that a midwife is qualified to attend all cases of natural labour-that is, she undertakes the cases herself without a doctor, and is, in fact, engaged instead of one."

I think, Sirs, the above quotations show clearly that the promoters of this iniquitous Bill propose $(a)$ to exclude medical students from lying-in hospitals for training; $(b)$ to exclude all resident medical officers; $(c)$ to exclude all visiting medical staffs; (d) to exclude the district Poor-law medical officers from attending Poor-law confinements, and. (e) generally to degrade and prostitute the Miedical Act, 1886 , and to revert to those death-dealing times when midwifery was an occupation of the uneducated and dangerous. At least thirteen women die each day in England in childbed. Is not this sad and disgraceful death-rate-not to mention the sick and maimed rates-sufficient to prompt us to insist on the elevation of the practice of midwifery to a much higher level than it occupies to-day, and to do everything to prevent its degradation and retardation?

I am, Sirs, yours faithfully,

Liverpool, April 15th, 1896 Robert R. RENTOLL.

\section{"THE EFFECT OF MUSCULAR WORK UPON THE ALKALINITY OF THE BLOOD." To the Editors of THE LANCET.}

SiRs,-In The LANCET of April 11th (p. 1020) Mr. Fotheringham contrasts a statement of mine in THa LixceT of March 7th (p. 611) with one in the paper by Dr. Hutchison which follows it, and asks, "Which is the correct view?" I reply that probably both are correct. as their opposition is apparent rather than real. The conclusion I draw from $\mathrm{my}$ facts and figures (p. 614) is " that the effest of exercise is to increase the function of urea," and as I have pointed out in my book that the excretion of urea and of acid in the urine 